\title{
Object-oriented Ferromanganese Furnace Model
}

\author{
STEIN O. WASB $\varnothing *$, BJARNE A. FOSS $\dagger$ and RAGNAR TRONSTAD* \\ Keywords: Object-oriented programming, industrial furnace, metallurgy, process \\ model
}

The high-carbon ferromanganese furnace is a semi-continuous unit process, with a number of complex, and partly unknown mechanisms taking place inside it. The furnace operation has been characterized by fluctuations in vital process variables. Many of the operational problems are caused by the lack of information about the internal conditions. This paper presents an object-oriented model of the furnace and its future application in monitoring the furnace conditions. The object-orientation ensures that the model becomes easy to modify as new process knowledge is collected.

\section{Introduction}

One of the major difficulties in operating electric ferromanganese furnaces today is the lack of information on the internal furnace conditions. Furnace operation will improve if critical process variables can be computed or estimated on-line, since the operators and metallurgists then will be able to take better decisions on how to run the furnace.

The existing process knowledge is represented in different types of models, ranging from stringent mathematical models to rather vague assumptions on which direction the process variables seem to go in certain situations. In this paper, focus will be made on first principles modelling of mass and energy balances.

The purpose of the model is to 1) increase the understanding of the dynamics of the furnace, 2) use the model in an operator support system and 3) investigate a technique that makes it possible to easily change parts of the model and apply different model representations within the same framework. Simulations on a reliable model can predict the furnace conditions some hours or days ahead. The operators may, hence, take action at an early stage to prevent poor furnace conditions. The third point is important for efficient process modelling. By efficient is meant the ability to easily change the model, e.g. by including new chemical substances or changing thermochemical properties.

To aid modelling of details within complex unit processes, a graphical model representation has been defined. This representation is briefly described in Sec. 2. In Sec. 3 the process is modelled using first principles knowledge. The model is validated using process data from furnace no. 11 at Elkem Mangan KS PEA. Finally, future use of the model in an operator support system is discussed before some concluding remarks are given.

*Elkem ASA Research, P.O. Box 8040 Vågsbygd, N-4602 Kristiansand, Norway, e-mail: [Stein.Wasbo, Ragnar.Tronstad]@elkem.no.

†Department of Engineering Cybernetics, Norwegian University of Science and Technology, N-7034 Trondheim, Norway, e-mail: Bjarne.Foss@itk.ntnu.no.

Received 23 May 1997.

This paper was presented at the IFAC Symposium on Advanced Control of Chemical Processes (ADCHEM-97), Banff, Canada, June 1997, and is reprinted with permission from Elsevier Science Ltd. 


\section{Process Abstraction}

When a mathematical process model is developed, a graphical sketch of the process is often the first step. This sketch of the process is, however, most often an informal description. The modeller has to interpret the figure based on his knowledge about the process. Drengstig et al. (1996) present a formalized graphical description, where each symbol has a unique interpretation. A network of these symbols may, hence, be interpreted automatically. This formal graphical representation is used here, as a basis for the object-oriented modelling approach.

\subsection{Graphical representation}

A process can generally be abstracted as being a network consisting of devices (representing accumulation) and connections (representing flow) (Marquardt, 1994). Devices and connections are called topological components and are symbolized as depicted in Fig. 1.

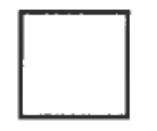

phase

$$
\vdots^{-\cdots} \vdots
$$

environmental terminal

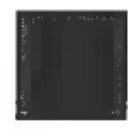

controller phase

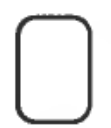

connection

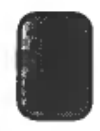

signal transformer

a) Devices

b) Connections

Figure 1. Symbols for devices and connections.

The devices and connections are connected by double lines, as shown in Fig. 2. If only a part of a process is to be shown, the interface between the part that is shown, and the surrounding subprocesses is illustrated by a circle. The signal line arrow is used to illustrate signal flow (e.g. control signal, measurement signal).

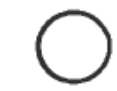

relation to higher level component

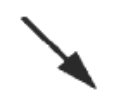

signal line rentine

\section{component connecting} line

Figure 2. Other symbols.

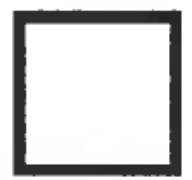

composite device

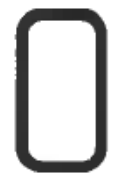

composite connection

Figure 3. Symbols representing composite topological components. 
A network of devices and connections may be aggregated into composite devices and connections. This is symbolized by thick lines, as shown in Fig. 3.

Inside each of the devices and connections, there is a network of phenomenological components. The phenomenological components represent accumulation and flow of species and energy. The types of phenomenological components vary depending on where they occur. This is illustrated in Fig. 4. The arrows are used to connect the phenomenological components. Unidirectional arrows indicate the flow of the different chemical species and energy. Bidirectional arrows are used to indicate equilibrium e.g. between phases or equilibrium reactions.

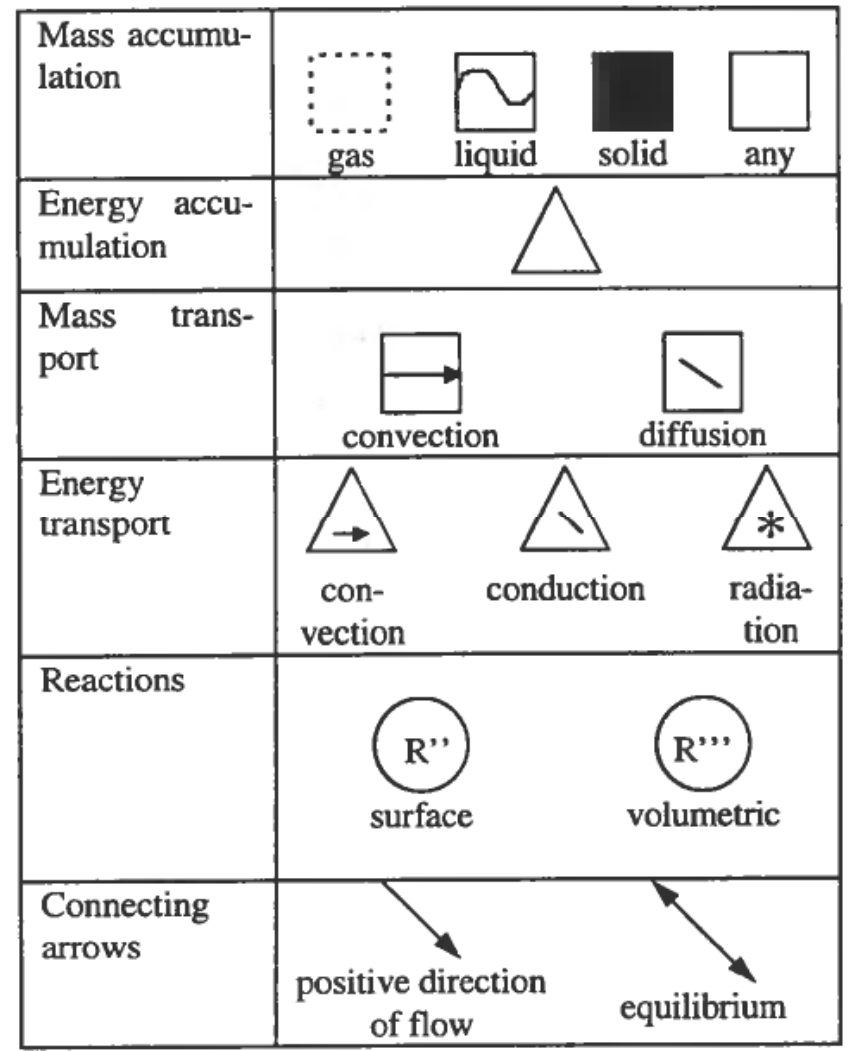

Figure 4. Symbols for phenomenological components.

\subsection{The object-oriented approach}

The graphical model representation is used as a basis for an object-oriented implementation. Each symbol in the graphical representation is associated with objects instantiated from a set of classes. In object oriented programming languages (OOPL), the data structure and the operations are incorporated in discrete objects, as opposed to traditional procedural programming languages, where the data structure and the methods working on the data are separated. Object-orientation offers mechanisms like classification, inheritance, encapsulation and polymorphism (Rumbaugh 1991). Using these mechanisms in a reasonable manner means that 1) programming code may be reused in a much larger extent than ordinary programming languages support, 2) the inner representation of an object may be hidden for other objects, and 3) an object may be specialized if necessary. 
An OOPL enables us to develop a model that consists of a number of modules, connected through well-defined interfaces. This is an advantage in the modelling process, where, typically, the structure of the process is known, but the content of each part needs to be modified. The representation of a subprocess inside a module may be hidden from the surrounding modules as long as the interface between the modules is well defined. The programming language $\mathrm{C}++$ (Stroustrup 1991) has been used to implement the modelling approach.

A first principles mathematical description of a process, using mass and energy balances is used in this work. The modelling approach is directed towards simulation. Hence, the ordinary differential equations (ODEs) describing the dynamical behaviour of the system are solved numerically by an equation solver.

\section{Metallurgical Process Model}

In this section a dynamic model of the metallurgical system of the furnace is being developed. Fig. 5 illustrates how the furnace consists of furnace zones, in which different phenomena take place. In the upper parts of the charge, water evaporates, and the ore is partly reduced. In higher temperature ranges, deeper down in the furnace, the reduction of the ore in the solid state continues. In the hearth of the furnace the ore melts and reacts with carbon, forming metal. At the bottom, slag and metal are tapped from the slag/metal zone. There are 21 different species considered in the model, taking part in 15 different reactions. Five different phases are considered: solid/liquid (in the prereduction zone), solid (carbon in the coke-bed), gas, slag and metal. For a more detailed description, see Wasbø (1996).

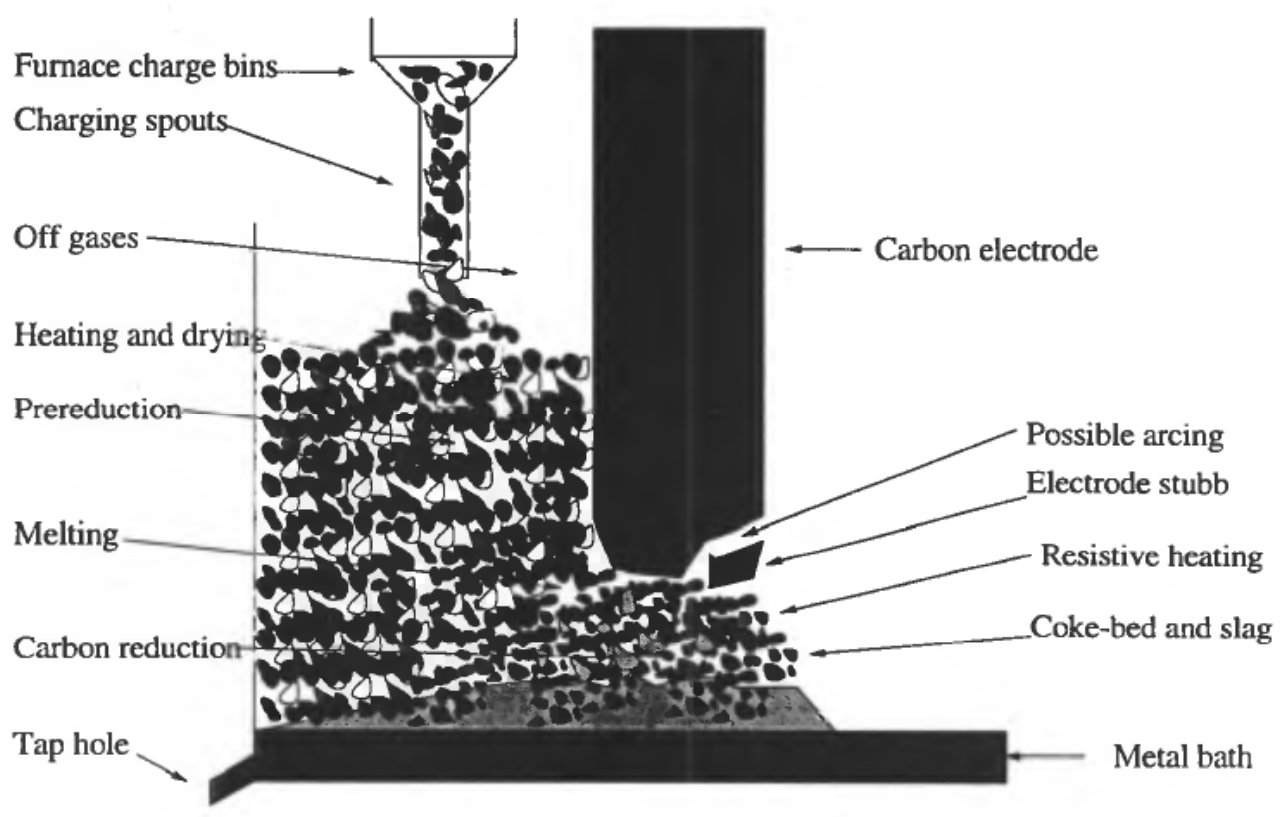

Figure 5. Sketch of the metallurgical system of a HC-FeMn furnace. 


\subsection{The prereduction zone}

In the upper parts of the furnace, here denoted by the prereduction zone, water evaporates, the manganese and iron oxides with high contents of oxygen will be reduced by counter-current carbonmonoxide, and carbonates will decompose. In addition, the Boudouard reaction will take place in the prereduction zones.

The reactions and phase transitions considered in the production zones of this model are:

$$
\begin{aligned}
\mathrm{Fe}_{2} \mathrm{O}_{3}+\mathrm{CO}_{(g)} & \rightarrow 2 \mathrm{FeO}+\mathrm{CO}_{2(g)} \\
\mathrm{FeO}+\mathrm{CO}_{(g)} & \rightarrow \mathrm{Fe}+\mathrm{CO}_{2(g)} \\
3 \mathrm{MnO}_{2}+2 \mathrm{CO}_{(g)} \rightarrow \mathrm{Mn}_{3} \mathrm{O}_{4}+2 \mathrm{CO}_{2(g)} & \\
3 \mathrm{Mn}_{2} \mathrm{O}_{3}+\mathrm{CO}_{(g)} & \rightarrow 2 \mathrm{Mn}_{3} \mathrm{O}_{4}+\mathrm{CO}_{2(g)} \\
\mathrm{Mn}_{3} \mathrm{O}_{4}+\mathrm{CO}_{(g)} & \rightarrow 3 \mathrm{MnO}+\mathrm{CO}_{2(g)} \\
\mathrm{CaCO}_{3} & \rightarrow \mathrm{CaO}+\mathrm{CO}_{2(g)} \\
\mathrm{MgCO}_{3} & \rightarrow \mathrm{MgO}+\mathrm{CO}_{2(g)} \\
\mathrm{MnCO}_{3} & \rightarrow \mathrm{MnO}+\mathrm{CO}_{2(g)} \\
\mathrm{H}_{2} \mathrm{O} & \rightarrow \mathrm{H}_{2} \mathrm{O}_{(g)} \\
\mathrm{H}_{2} \mathrm{O}_{(g)} & \leftrightarrow \mathrm{H}_{2(g)}+\mathrm{CO}_{2(g)} \\
\mathrm{C}+\mathrm{CO}_{2(g)} & \rightarrow 2 \mathrm{CO}_{(g)}
\end{aligned}
$$

The reactions are both elementary reactions and the result of two or more such mechanisms. As an example, $\mathrm{Fe}_{2} \mathrm{O}_{3}$ reacting with $\mathrm{CO}$ will form $\mathrm{Fe}_{3} \mathrm{O}_{4}$, which in turn will react with $\mathrm{CO}$ gas, forming $\mathrm{FeO}$. These two mechanisms have been lumped into one, in order to reduce the number of species and reactions.

\subsection{The coke-bed}

In the coke-bed, the following reactions are considered the most important:

$$
\begin{aligned}
(\mathrm{MnO})+C_{(s)} & \rightarrow \underline{\mathrm{Mn}}+\mathrm{CO}_{(g)} \\
\left(\mathrm{SiO}_{2}\right)+2 C_{(s)} & \rightarrow \underline{S i}+2 \mathrm{CO}_{(g)} \\
C_{(s)} & \rightarrow \underline{2} \underline{C}
\end{aligned}
$$

where the parentheses denote slag phase. The underlined species are in metal phase.

\subsection{The slag and metal zone}

The slag and metal collects in the bottom of the furnace. Due to the different densities of the two phases, the slag will float on top of the metal. In this model, the slag and metal zone is defined to contain both the slag and the metal phase.

Only one reaction is considered important in this furnace zone:

$$
2(\mathrm{MnO})+\underline{\mathrm{Si}} \leftrightarrow 2 \underline{\mathrm{Mn}}+\left(\mathrm{SiO}_{2}\right)
$$




\subsection{Object-oriented model}

Conceptually, the furnace has been divided into three types of zones, as described above: 1) prereduction zones, 2) coke-bed and 3) slag and metal zone. These three zone types define the three different zone classes which are all of the same superclass. This is shown in Fig. 6. A raw material source is connected to the upper prereduction zone, and a gas sink and a liquid sink are linked to the upper prereduction zone and the slag/metal zone respectively. Energy is provided by the electrodes, and there are some heat losses to the surroundings.

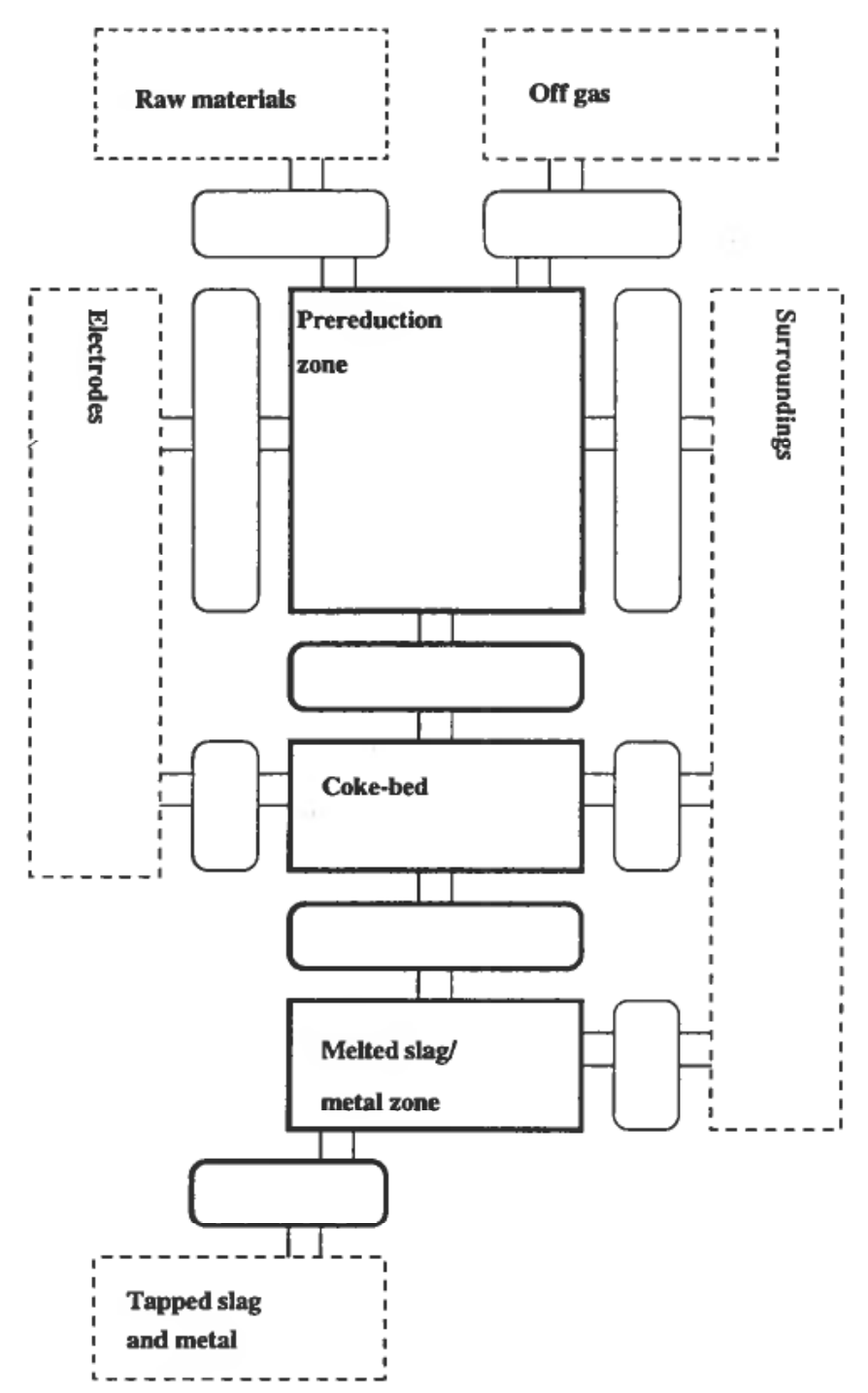

Figure 6. Sketch of the shaft model.

In each zone there is a set of species and reactions. The species are modelled as objects inside the furnace zones. Reactions are also defined as objects, defining relations between the species. Fig. 7 shows the details at a phenomenological level of the flow and reaction mechanisms in the prereduction zone related to chemical species containing manganese. 


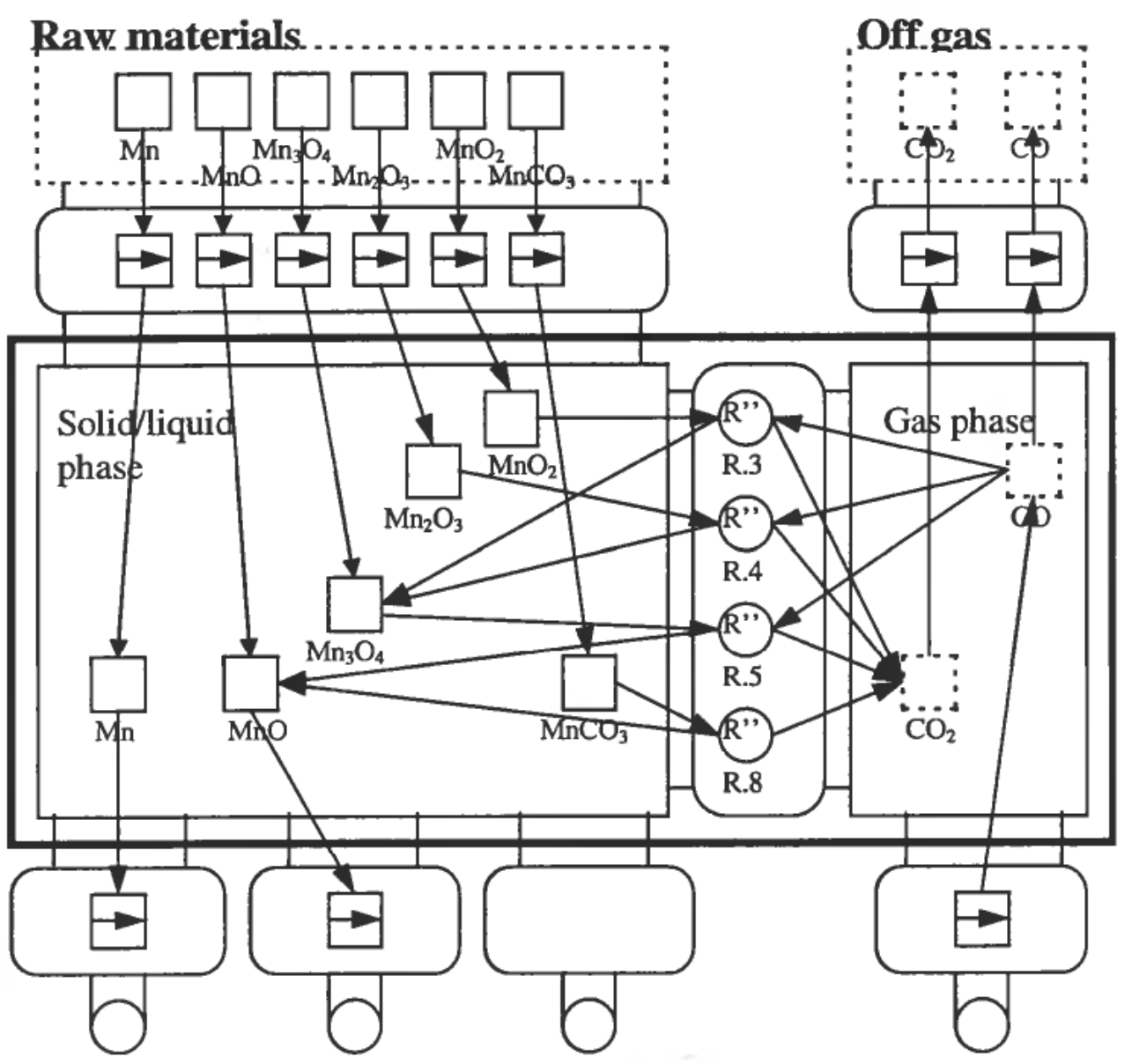

Figure 7. Formal graphical representation of the phenomena in the prereduction zone related to chemical species containing manganese.

\subsection{Mass and energy balances}

The fundamental conservation laws form the differential equations describing the dynamic behaviour of the furnace zones, and hence the dynamic behaviour of the whole furnace. The balance equations are derived on a general basis, looking at the phases solid/liquid and gas separately, starting with the solid/liquid phase.

In the following equations, the index parameter $z$ runs through the prereduction zones, starting at the top. Thus, index $z-1$ refers to the zone above zone $z$. An index reading $z-1, z$ is used in relation with flow from zone $z-1$ to zone $z$.

This notation is used in the following:

$\mathbf{n}_{g}, \mathbf{n}_{s} \quad$ Vector containing the number of moles of gas and solid/liquid components, respectively.

$\mathbf{F}_{s, z, z+1}$ Vector containing the number of moles of solid/liquid components flowing from zone $z$ to zone $z+1$. Likewise for the gas phase.

$\mathbf{r}_{2} \quad$ Vector containing the reaction rates.

$\mathrm{S}_{s, z} \quad$ Matrix containing the stoichiometric relations between the species taking part in the reactions in zone $z$. 
Solid/liquid phase. The general component balance is given by the vector equation:

$$
\frac{d \mathbf{n}_{s, z}}{d t}=\mathbf{F}_{s, z-1, z}-\mathbf{F}_{s, z, z+1}+S_{s, z} \mathbf{r}_{z}
$$

The internal chemical energy is the dominant energy form, and the other energy forms can be neglected. Hence, the conservation of energy is given by:

$$
\frac{d U_{s, z}}{d t}=\mathbf{F}_{s, z-1, z} \mathbf{H}_{s, z-1}-\mathbf{F}_{s, z, z+1}^{T} \mathbf{H}_{s, z}+Q_{e l}-Q_{l o s s}-Q_{s g, z}+Q_{s, z+1, z}-Q_{s, z, z+1}
$$

where $\mathbf{H}_{s, z}$ is a vector of the enthalpy of the solid state species in zone $z$.

Assuming that $d U=\mathbf{c}_{\mathrm{v}, \mathrm{s}}{ }^{\mathrm{T}} \mathrm{d}\left(\mathbf{n}_{\mathrm{s}, \mathrm{z}} \mathrm{T}_{\mathrm{s}, \mathrm{z}}\right)$ the temperature can be found, either by bringing the energy balance to a temperature explicit form, or directly by solving the equation numerically.

The gas phase equations are modelled in a similar way, giving a set of balance equations for each component, and an equation for the energy balance.

Prereduction flow calculations. The volume of the prereduction zones is assumed constant, which leads to the following volumetric flow between two zones:

$$
q_{s, z-1, z}=K_{s}\left(V_{s, z, \text { avail }}-V_{s, z}\right)+q_{s, z, z+1}-q_{s, z, r}
$$

Coke-bed flow mechanisms. The flow into the coke-bed is assumed to be determined by the melting rate of the materials descending from the prereduction zone. The flow out of the coke-bed is given by the viscosity of the liquids in the coke-bed.

Slag/metal flow. The flow of slag and metal out of the furnace is determined by the opening and closing of the taphole. In the simulations presented in the next section, the flow of slag and metal out of the furnace is given by data from the furnace operation at Elkem Mangan KS PEA.

\subsection{Simulations}

The model will be validated using different criteria, such as: 1) the predictive capabilities of the model by simulation, and 2) how the model reflects the knowledge process experts and operators have gained over years of experience.

The dynamic model presented above has been implemented in $\mathrm{C}++$, with a resolution of five and ten gas reduction zones. In this section some simulation results using five gas reduction zones are presented.

The following measurements from furnace no. 11 at Elkem Mangan KS PEA have been used for model validation:

- Slag analysis: $\mathrm{Al}_{2} \mathrm{O}_{3}, \mathrm{CaO}, \mathrm{MgO}, \mathrm{MnO}, \mathrm{SiO}_{2}$

- Metal analysis: $\mathrm{C}, \mathrm{Fe}, \mathrm{Mn}, \mathrm{Si}$

- Off-gas analysis: $\mathrm{CO}, \mathrm{CO}_{2}, \mathrm{H}_{2}$

Note that the only inputs in the simulations are: 1) charge mix, 2) amount of tapped metal, and 3) furnace load. No data has been applied to adjust the model output on-line.

Simulation validation. Fig. 8 shows how well the model is able to track the amount of $\mathrm{Al}_{2} \mathrm{O}_{3}$ in the slag. The simulated value follows the measure value well, until the end of November, when a deviation can be observed. Simulation results for the other slag 

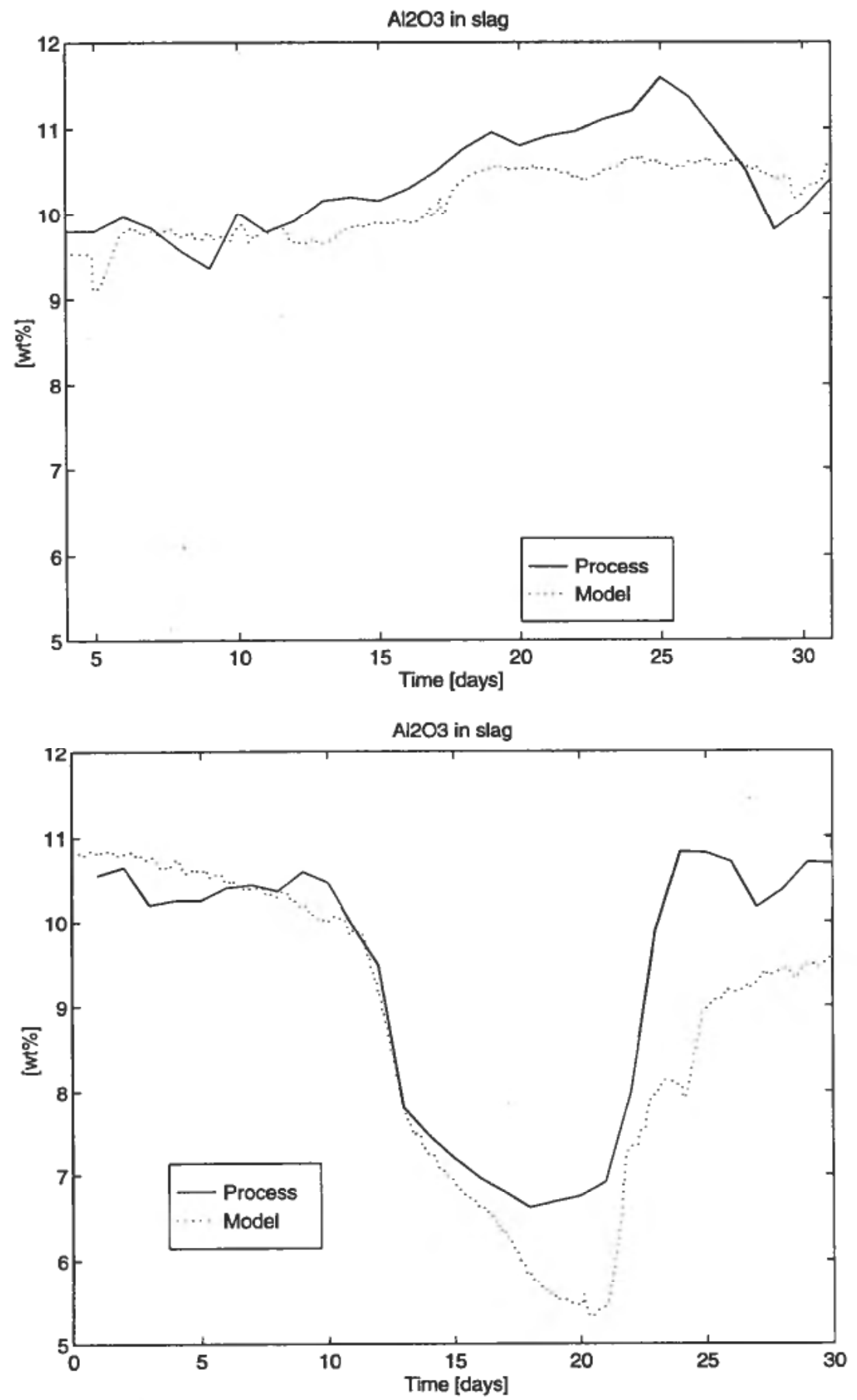

Figure 8. Model validation: $\mathrm{Al}_{2} \mathrm{O}_{3}$ in the slag. October 1993 (left) and November 1993 (right).

components show similar results. Simulation plots of $\mathrm{MnO}$ in the slag show that the model could be improved. The reduction of $\mathrm{MnO}$ is the main process in the furnace, and the reaction is sensitive to changes in the melting and reduction conditions in the coke-bed. Hence, the description of the coke-bed in this model may be too simple to describe all the variations in the process. 

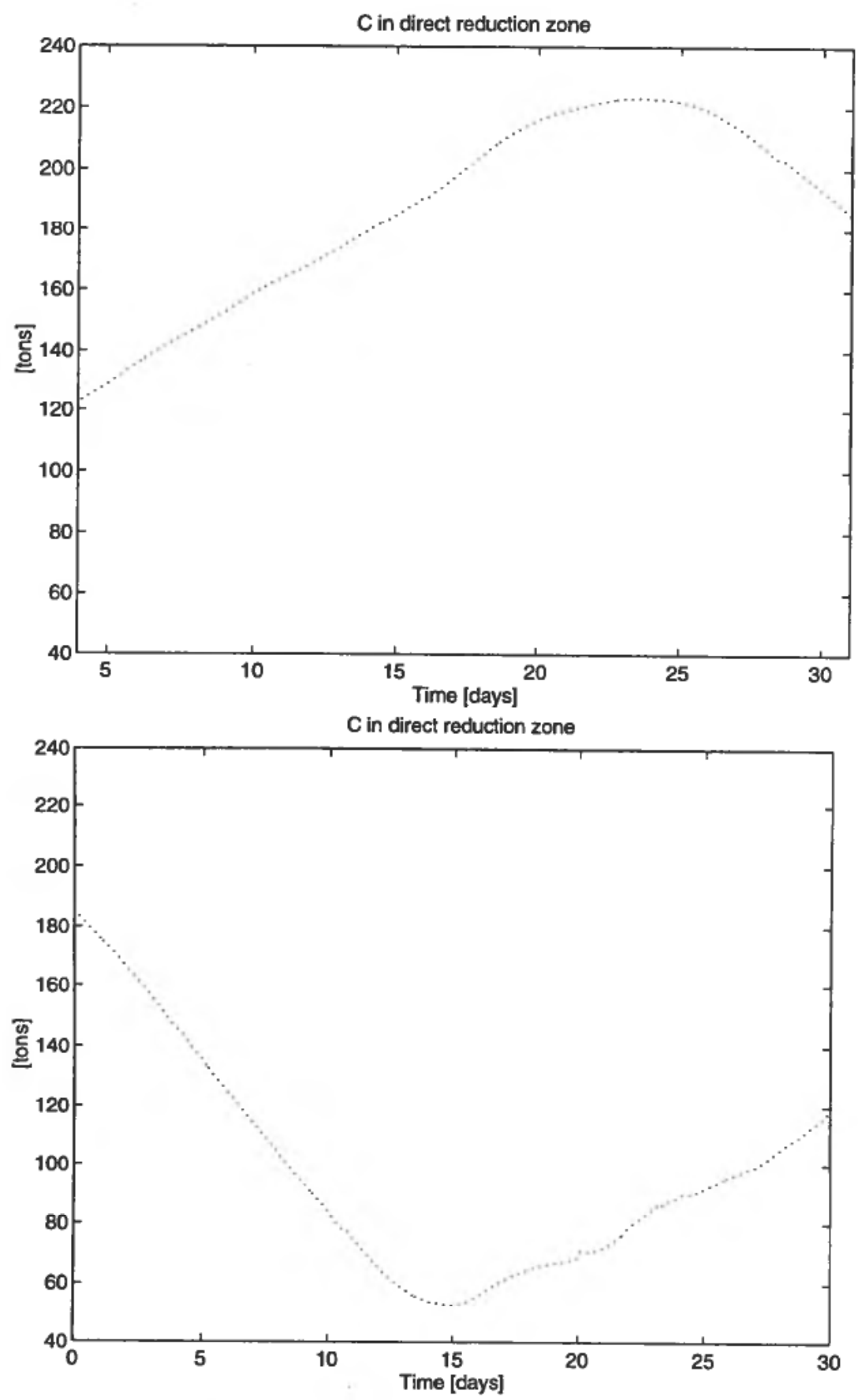

Figure 9. Accumulated carbon in the coke-bed. October 1993 (left) and November 1993 (right).

Fig. 9 shows how the predicted amount of accumulated carbon in the coke-bed changes over the same period. There is a buildup of carbon until the 24th of the month, when the amount of accumulated carbon starts to descend. The trend from October continues until the 15th November, when the trend is slowly reversed, and carbon again starts to accumulate. 
This is in good agreement with the furnace operation log. The furnace was believed to be sightly overcoked. The amount of carbon in the feed was slowly decreased. Then, at about the 10th, there were problems with short electrodes, and the furnace showed signs of undercoking. At this point actions were taken to correct the coke-balance, and the amount of coke in the fed charge was dramatically increased. This shows that using the model to predict the accumulation of coke would be useful for furnace operation.

\section{Discussion}

An advantage of the object-oriented modelling technique chosen here is that the model is generically hybrid, in the sense that any representation can be used inside the devices and connections as long as the interfaces to the other modules are preserved.

Another advantage is that the modularity and the graphical representation makes it easy to visualize the objects and the connections between them. This facilitates communication between people during model development.

The simulations show that the model can be applied to answer important questions about the inner furnace conditions that are difficult, if not impossible to answer with the available instrumentation. Comparing the simulations above with the furnace operation log, it is clear that problems regarding over- or undercoking of the furnace, could have been avoided if a dynamic model had been applied in process monitoring.

The model will be used in an operator support system to aid one or more of the following items: 1) on-line process monitoring and parameter estimation, 2) off-line hypothesis testing and analysis of historical data, 3) prediction of input changes and 4) off-line operator training.

\section{ACKNOWLEDGEMENT}

This work has been financially supported by Elkem ASA and The Research Council of Norway through the research programme EXPOMAT. The authors would like to thank professor Sverre E. Olsen at The Department of Metallurgy and Dr Halvard Tveit at Elkem ASA for helpful discussions and for their enthusiasm and encouragement.

\section{REFERENCES}

Drengstig, T., WASB $\emptyset$, S. O. and Foss, B. A. (1996). A formal graphical process modeling methodology. Technical report. Department of Engineering Cybernetics, Norwegian University of Science and Technology, Trondheim, Norway.

MarquardT, W. (1994). Trends in Computer-Aided Process Modeling. Computers chem. Engng., 20, 591-609.

Rumbaugh, J., Blaha, M., Premerlani, W., Eddy, F. and Lorensen, W. (1991). ObjectOriented Modeling and Design. Prentice Hall.

STROUSTRUP, B. (1991). The C ++ programming Language. Addison-Wesley.

WASB $\emptyset$, S. O. (1996). Ferromanganese Furnace Modelling Using Object-Oriented Principles. Dr.Ing. thesis. Department of Engineering Cybernetics, Norwegian University of Science and Technology, Trondheim, Norway. ISBN 82-7119-970-6. 